\title{
THE MICROVASCULAR ARCHITECTURE OF TERM FOETAL AND NEONATAL RABBIT LUNGS: A SCANNING ELECTRON MICROSCOPIC COMPARISON
}

\author{
Jill LiPsett $^{1}$, Osamu Ohtani ${ }^{1,2}$, Glen Gole $^{3}$ and Bren Gannon ${ }^{1,4}$ \\ Departments of ${ }^{1}$ Anatomy and Histology, and ${ }^{3}$ Ophthaimology, School of Medicine, The Flinders Univer- \\ sity of South Australia, Bedford Park, South Australia 5042, Australia
}

\begin{abstract}
The microvascular architecture and the distribution of vascular resistance in the lungs of full term foetal and neonatal rabbits were studied by scanning electron microscopy of microvascular corrosion-casts and of specimens that had been perfusion-fixed by osmium. In the foetus, each potential air space was surrounded by its own capillary plexus; there were occasional, short anastamoses with adjacent plexuses. In the folded and compressed parenchymal tissue, two 'lobule' states were identified, one in which the vasculature was easy to perfuse, either with fixative or plastic, and another in which flow was impeded. In the neonatal lung the parenchyma was inflated and the terminal air sacs rounded. The same capillary plexus arrangement was seen as in the foetus, but the perfusion of all the lobules was uniform. These findings suggest that the high pulmonary vascular resistance in the foetus is distributed unevenly. Such a system would allow maintenance of blood velocity sufficient to prevent sludging and stasis in the perfused, lower resistance areas, whilst total blood flow remained low. A cyclical pattern of perfusion/non-perfusion of the lobule units over time would maintain both vascular resistance and uniform lung development. The recruitment of the non-perfused areas at birth would rapidly drop pulmonary vascular resistance, and accommodate the vital increase in pulmonary blood flow at reduced perfusion pressures.
\end{abstract}

Before birth the mammalian pulmonary vascular bed has a high resistance; only $7-10 \%$ of combined ventricular output perfuses the pulmonary vessels (8), although the pulmonary trunk pressure is at a (foetal) systemic level. As the newborn begins to breathe, pulmonary blood flow rapidly increases and the ductus arteriosus closes. Within a few weeks

\footnotetext{
${ }^{2}$ Present Address: Department of Anatomy, Okayama University; Medical School, Okayama 700, Japan

${ }^{4}$ To whom reprint request should be addressed
}

postnatally, pulmonary vascular resistance has decreased to $2.5-5.0 \%$ of the foetal value (5).

It is generally accepted that the initial postnatal drop in pulmonary vascular resistance is achieved by arteriolar dilatation following inflation of the lung with air (7). Foetal pulmonary arterioles, down to at least $15 \mu \mathrm{m}$ luminal diameter, contain substantially more medial smooth muscle in comparison to similar sized vessels in the adult (5). It is to these vessels that most of the foetal pulmonary vascular resistance is generally attributed. However the adaptive changes of the intrapulmonary circulation at birth remain poorly understood. 
In order to investigate pulmonary vascular perfusibility over the perinatal period, it was decided to observe these changes in foetal and neonatal rabbit lungs by studying microvascular casts and matched, perfusion-fixed tissue specimens, using scanning electron microscopy.

\section{MATERIALS AND METHODS}

Six New Zealand White rabbits at term gestation (31 days) were anaesthetized with Alfathesin (a 9:3 alphaxalone/alphadalone acetate mixture; Glaxo Australia, Melbourne) by ear vein infusion. Supplementary doses to a total of about $15 \mathrm{mg}$ were given throughout the procedure as required. The foetal rabbits ( $\mathrm{n}=$ 20 , weighing $28-32 \mathrm{~g}$ ) were exposed by lapa- rotomy and incision through the uterine wall. Half of each litter were removed, wrapped in tissue paper and placed on a heated pad. These neonates were allowed to breathe spontaneously for $30 \mathrm{~min}$. The remaining foetuses and the neonates were then anaesthetized with $0.02 \mathrm{ml}$, intraperitoneal injection of $60 \mathrm{mg} / \mathrm{ml}$ pentobarbital (Nembutal, Abbott, Sydney). In each animal the trachea was occluded by a tight ligature around the neck to prevent lung collapse. The heart was exposed by a mid-sternal incision and the pulmonary artery was cannulated with a polyethylene catheter $(0.86 \mathrm{~mm}$ internal diameter, Intramedic, Clay Adams, New Jersey) via a cut in the infundibulum of the right ventricle. A ligature through the transverse sinus secured the cannula and occluded the pulmonary

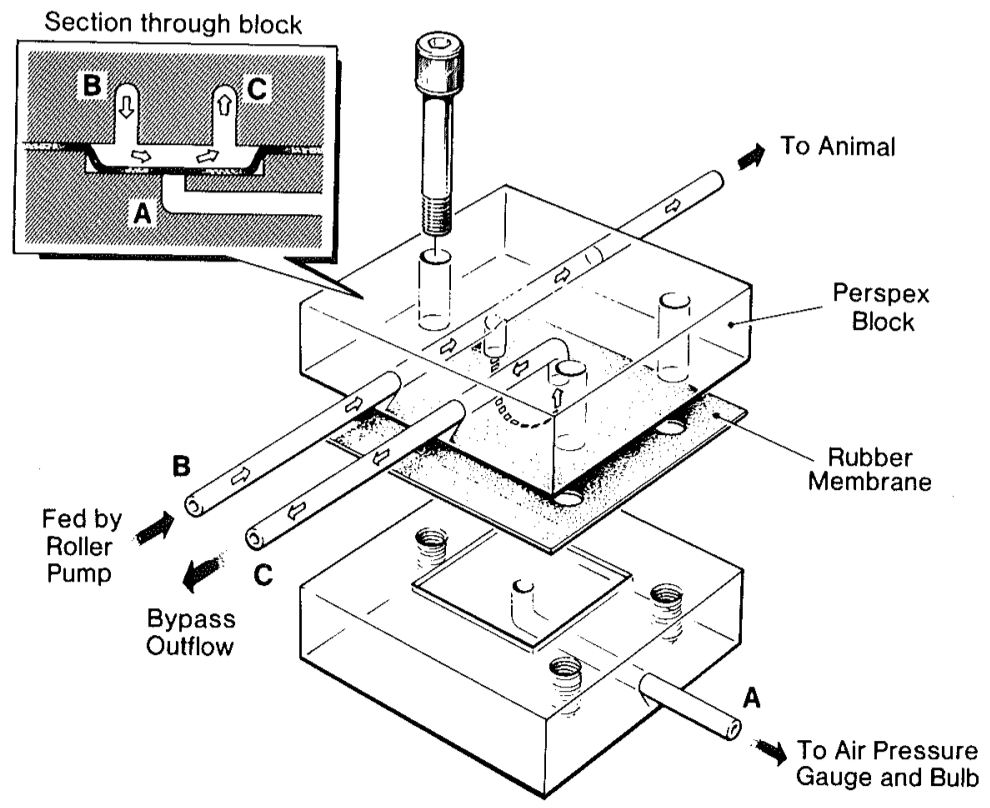

Fig. 1 Pressure limiting device: If the pressure in feeding line B exceeds the preset air pressure at $\mathbf{A}$ the rubber membrane is depressed, allowing bypass via $C$.

Table 1 Flow Rates, Maximum Perfusion Pressures and Air Pressures Used in the Fixation and Plastic Casting of the Foetal and Neonatal Lungs

\begin{tabular}{lccc}
\hline & $\begin{array}{c}\text { Flow rate } \\
(\mathrm{ml} / \mathrm{min})\end{array}$ & $\begin{array}{c}\text { Maximum perfusion } \\
\text { pressure }\end{array}$ & $\begin{array}{c}\text { Air pressure for } \\
\text { plastic infusion }\end{array}$ \\
\hline Foetus & 3.0 & $90 \mathrm{mmHg}$ & $120 \mathrm{mmHg}$ \\
Neonate & 3.0 & $80 \mathrm{mmHg}$ & $120 \mathrm{mmHg}$ \\
\hline
\end{tabular}


artery and aorta immediately distal to their respective valves. The left ventricle was opened to allow drainage of blood and perfusate from the pulmonary circulation. In all animals, the pulmonary vessels were flushed out with a heparinized $(10 \mathrm{IU} / \mathrm{ml})$ solution of polygelline (Haemaccel, Behring, F.R.G.), delivered at a predetermined flow rate by a roller pump (model MHRE 100, Watson-Marlow, Falmouth, U.K.). A pressure limiting device (Fig. 1) prevented the perfusion pressure from rising above physiological values (Table 1).

The heart and lungs were then prepared either by fixation or by plastic casting (6) (see below). Five neonates and five foetuses were included in each group.

\section{Fixation}

The pulmonary vasculature was perfused via the pulmonary artery catheter for 15 min with an osmium fixative of $\mathrm{pH} 7.4$ and osmolality of $350 \mathrm{mosm} / 1$, (2). The infusion cannula and left ventricular drainage site were then clamped and the preparation left for $1 \mathrm{~h}$. The heart and lungs were then removed and placed in a glutaraldehyde fixative of $\mathrm{pH} 7.4$ and 326 mosm/l (3). The air was removed from the neonatal lungs by placing the container of fixative and lung in an evacuation chamber with $650 \mathrm{mmHg}$ vacuum (gradually applied) for approximately $15 \mathrm{~min}$. They were left immersed in fixative at normobaria for several days.

Lobes of the lungs were taken and placed in $0.9 \%$ saline ( 3 changes for $1 \mathrm{~h}$ each), then $25 \%$ dimethylsulphoxide (DMSO) in $0.9 \%$ saline $(1 \mathrm{~h})$ and then 50\% DMSO $(1 \mathrm{~h})$. A frozen block of the final solution, containing the portion of tissue, was made by contact with a metal plate cooled with liquid nitrogen. A fractured surface was obtained by striking a hammer blow to a chisel in contact with the block. The fragments were allowed to thaw, returned to $0.9 \%$ saline via $25 \% \mathrm{DMSO}$, and then dehydrated in an ascending ethanol series $(25 \%, 50 \%, 70 \%$ and $100 \%)$. They were critical point dried, from $100 \%$ ethanol, in carbon dioxide (Pelco, Model $\mathrm{H}$ ) and mounted on metal stubs. The fractured surfaces were observed and photographed macroscopically before being sputter-coated with gold (Commonwealth Scientific Minicoater) and viewed with a Siemens/ETEC Autoscan Scanning
Electron Microscope at $20 \mathrm{kV}$.

\section{Plastic Casting}

The casting medium consisted of $20 \mathrm{ml}$ of methylmethacrylate monomer (Polysciences, Warrington, Pennsylvania) mixed with 250 mg benzoyl-peroxide (Polysciences), and prepolymerised with UV light to a viscosity between 3 and 4 centistokes at $20^{\circ} \mathrm{C}(1)$. Seven $\mathrm{ml}$ of 2-hydroxypropyl methacrylate (Polaron, Watford, U.K.) was added to $0.4 \mathrm{ml}$ of $N, N$ dimethylaniline (Merck, München, F.R.G.) immediately prior to injection, and the two mixtures combined. Air pressure (Table 1) was used to inject the plastic (1). As the plastic began to set, the inflow cannula was clamped. The preparations were placed in warm water overnight, before being transferred to $15-20 \%$ $\mathrm{w} / \mathrm{v}$ aqueous $\mathrm{KOH}$ solution until tissue digestion was complete. The casts were rinsed, firstly in hot water $\left(55^{\circ} \mathrm{C}\right)$ and then in running distilled water, and were then frozen while wet. They were fractured as described above and then air dried, mounted and sputter-coated for SEM observation.

\section{RESULTS}

\section{Foetal Lung}

Tissue specimens Macroscopically, the fractured surfaces of the osmium-fixed foetal lung showed two distinct areas. Blackened areas indicated regions where the osmium had perfused and been reduced, whereas in the interspersed white regions this had not occurred (Fig. 2a). The SEM clearly differentiated these areas as 1) regions of empty, 'flushed out' capillaries containing no blood cells, surrounding potential air sacs with a larger average luminal size, and 2) regions of more compact tissue with capillaries containing blood elements and surrounding potential air sacs of smaller luminal size (Fig. 3). Each area appeared to consist of up to $30-50$ potential air sacs in a particular fracture plane, and so probably represented a lung lobule.

The parenchymal tissue throughout the foetal lung was compressed and folded. The epithelia on opposite sides of many potential air sacs appeared almost in contact. The septum (the tissue layer separating adjacent potential air -sacs) was about $15 \mu \mathrm{m}$ in 

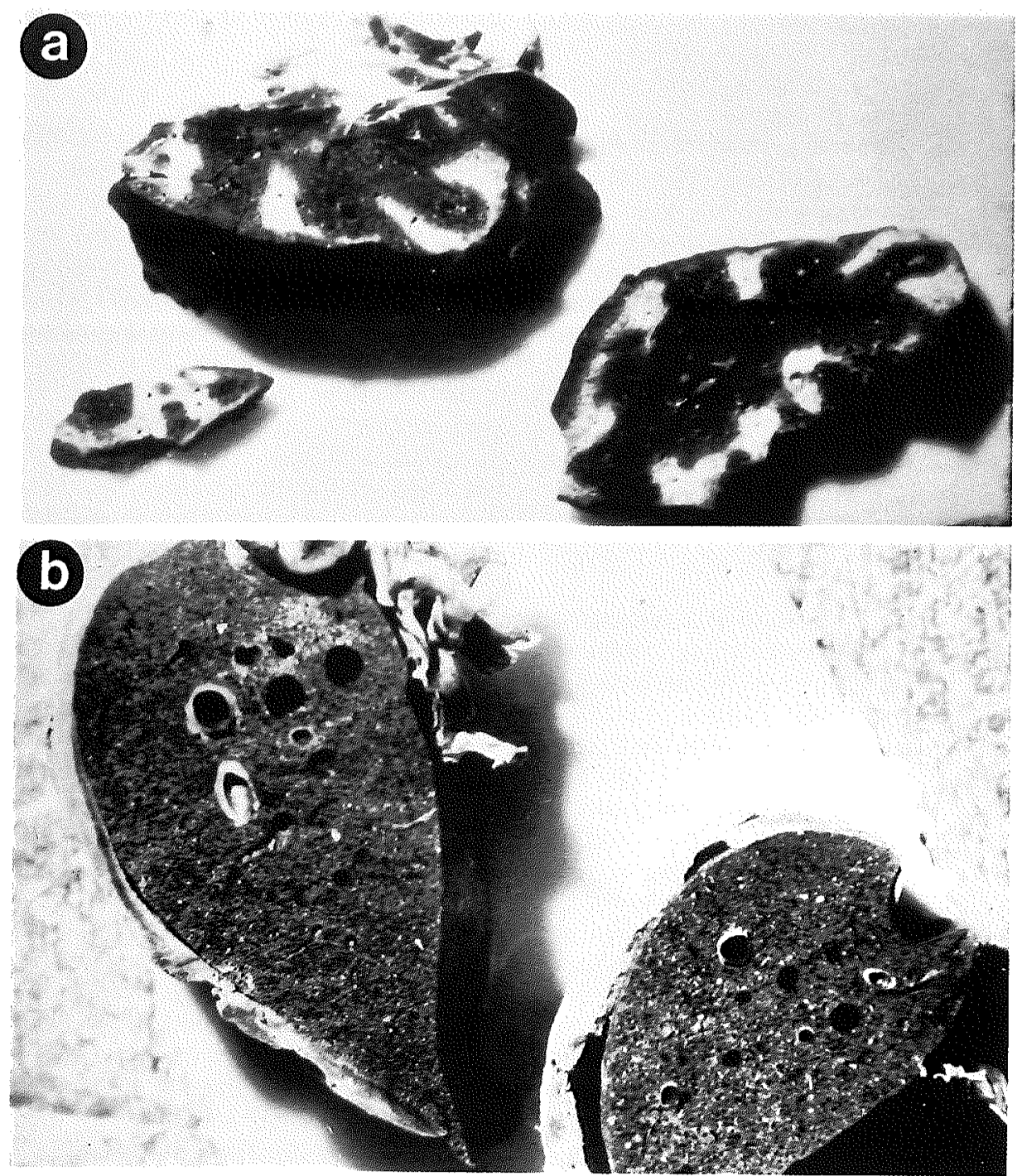

Fig. 2 Macrophoto of osmium perfusion fixed foetal $(a ; \times 14)$ and neonatal $(b ; \times 12)$ rabbit lung. In the foetus, black areas, where osmium perfusion and oxidation have occurred, are interspersed with white, indicating regions of variable vascular resistance. In the neonate, however, the perfusion of the fixative appears uniform.

thickness; it comprised a central connective tissue layer between two lines of capillary profiles, each underlying the epithelium of an air sac.

Vascular casts In the fractured surface of the cast specimens, two discrete (lobule sized) areas with either of two different cast appearances were evident: 1) in some areas the plastic had filled almost all of the vascular bed.
Short-segment capillaries anastamosed to form 4-7 sided polygons and this plexus surrounded each potential air sac. Thus the septum was seen to contain two vascular networks, one on each side, which anastamosed through occasional perpendicular vessels across it. Not all capillaries were filled and hence the plexus was not always complete. 2) There was an almost total filling deficiency. 


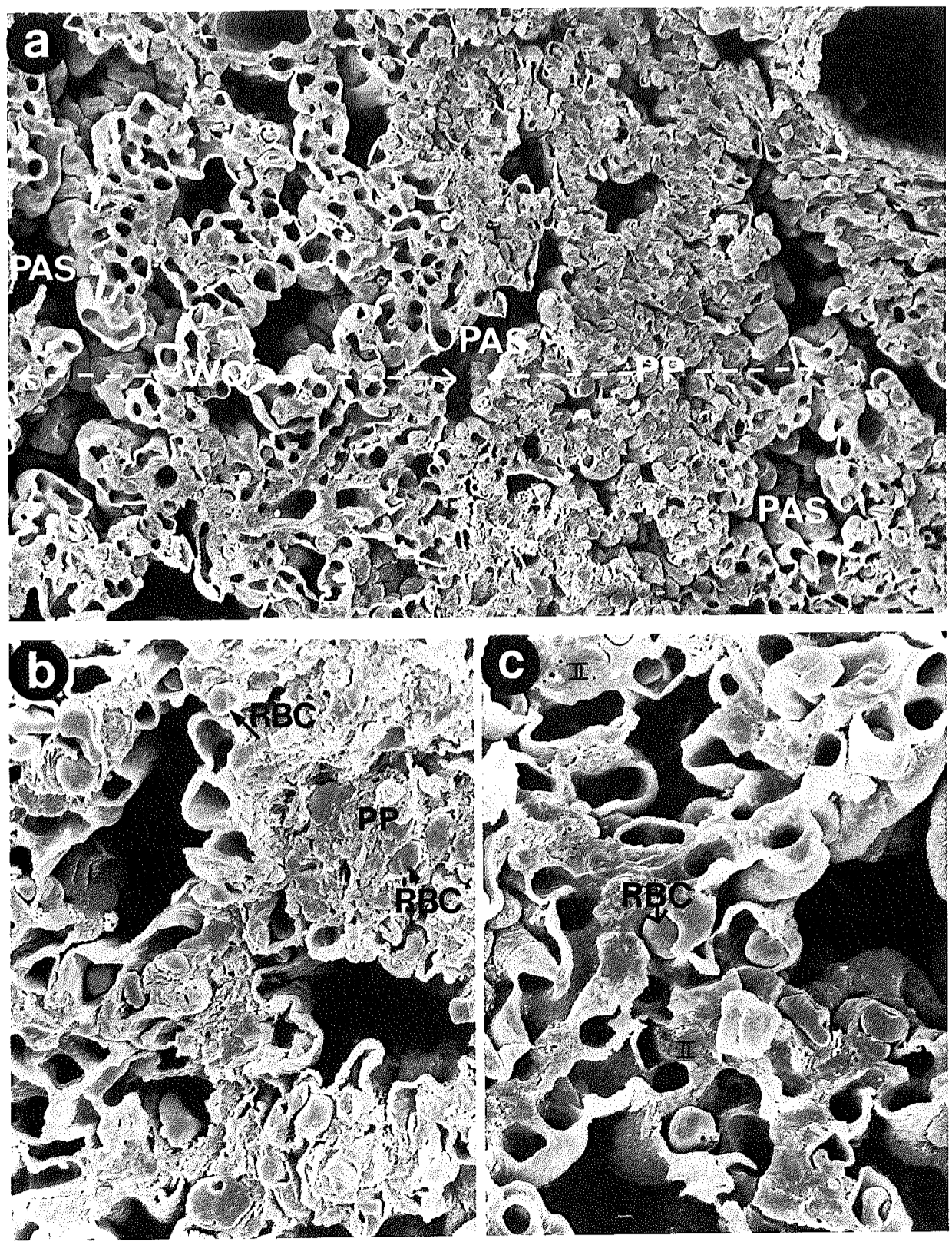

Fig. 3 Scanning electron microscopy of foetal lung tissue. a: Two distinct areas are seen. The well perfused area to the left (WO) shows empty capillaries in folded septa. The potential air spaces (PASs) are collapsed, showing slit-like cross-sections. The right area is poorly perfused $(\mathrm{PP})$, blood elements are present in the vascular space $(\times 500)$. In $\mathrm{b}$ and $\mathrm{c}$, the two areas are shown at higher magnification $(\times 1,360)$. $\mathrm{RBC}$, red blood cell; II, Type II cell 

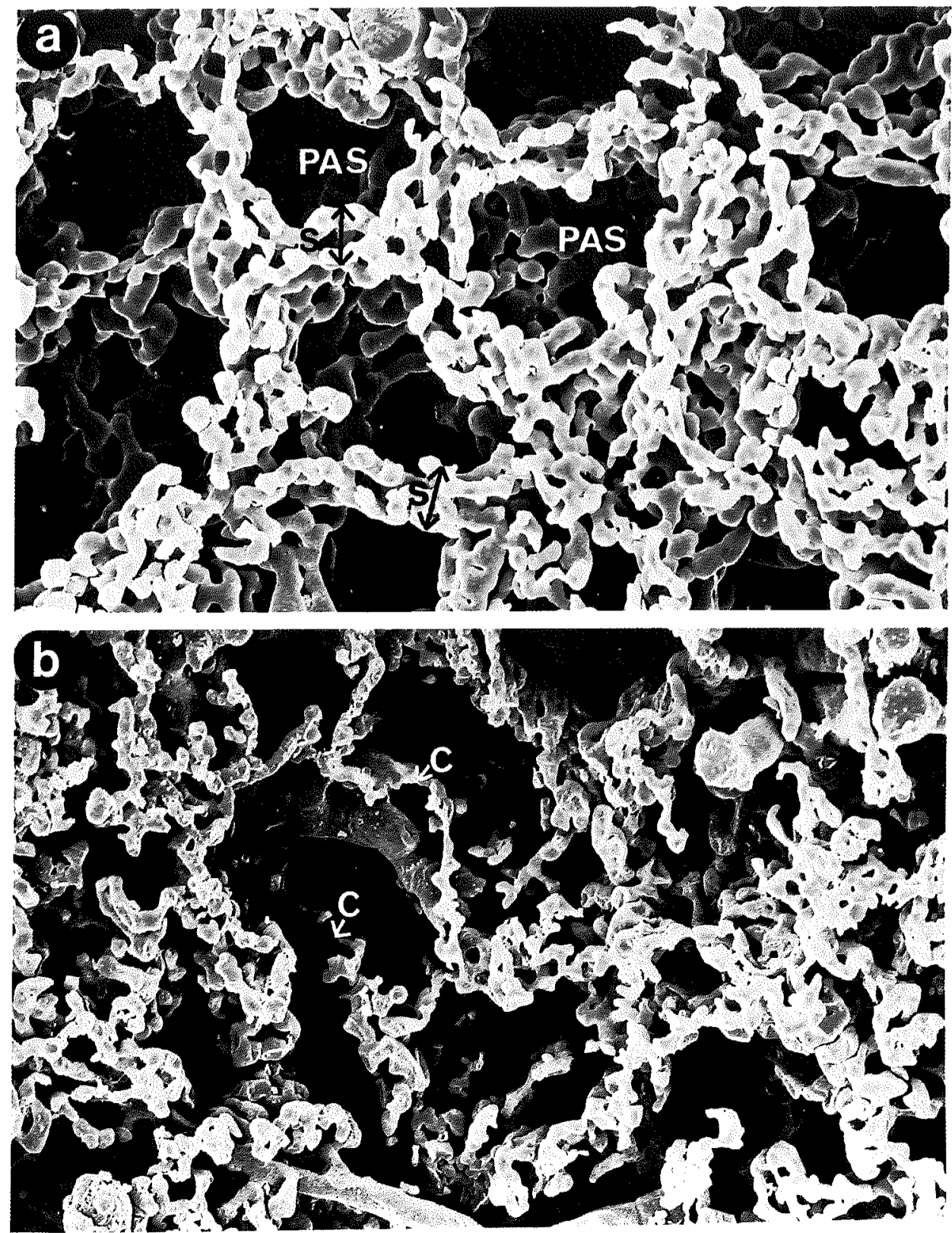

Fig. 4 Scanning electron microscopy showing foetal lung vascular cast. In a, the vasculature is extensively perfused. The potential air sacs (PASs) are recognizable and the capillaries lie in a dual plexus in the septal wall $(S) . \times 340$. In other areas $b$, the resistance to perfusion was higher and vasculature was poorly filled. A few long, erratic vessels (C) are present. $\times 350$ 

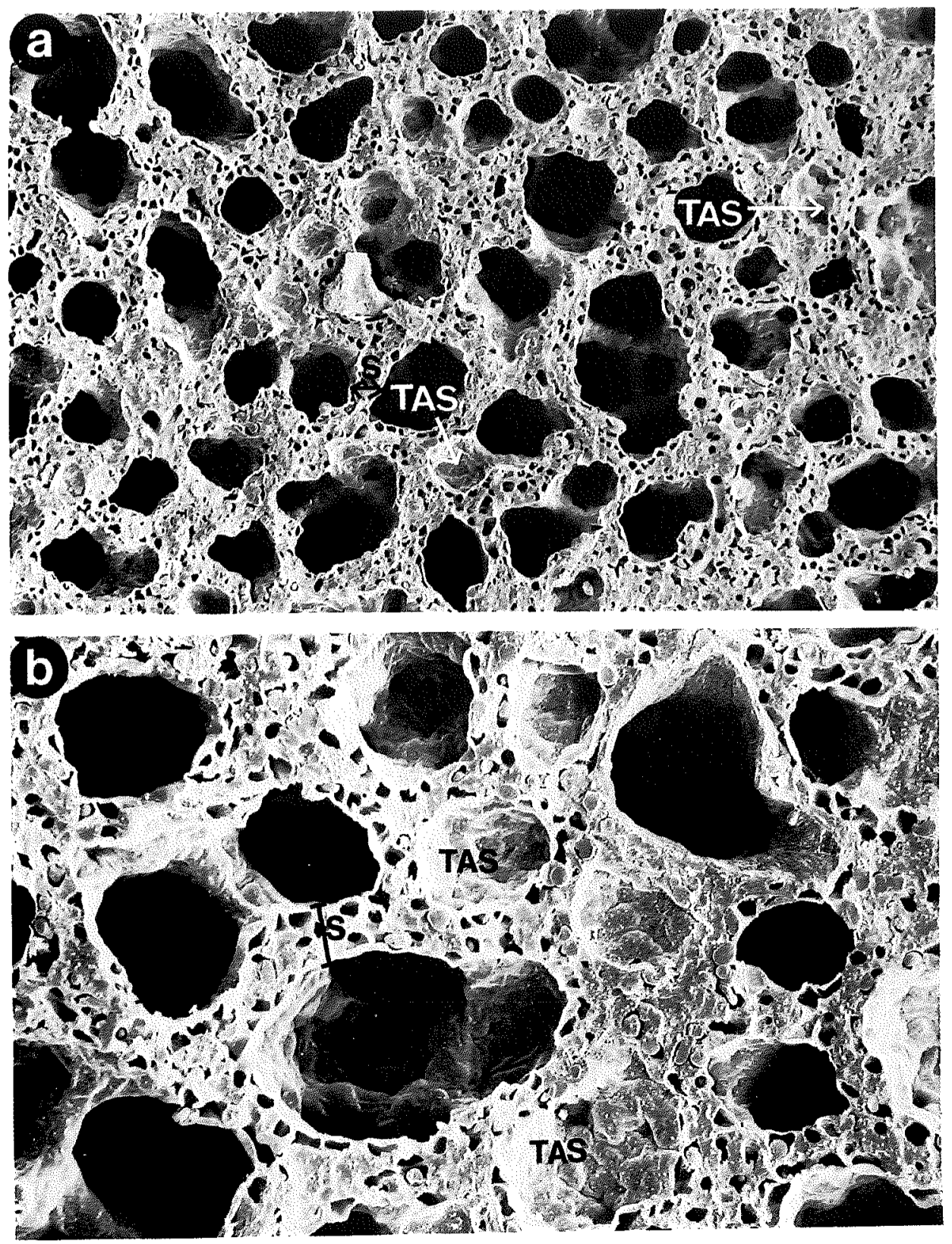

Fig. 5 Scanning electron microscopy of neonatal lung. a: $\times 250 ; b: \times 584$. The terminal air sacs (TASs) are rounded and each is surrounded by capillaries situated in the septum (S). Some random capillaries contain blood cells. 


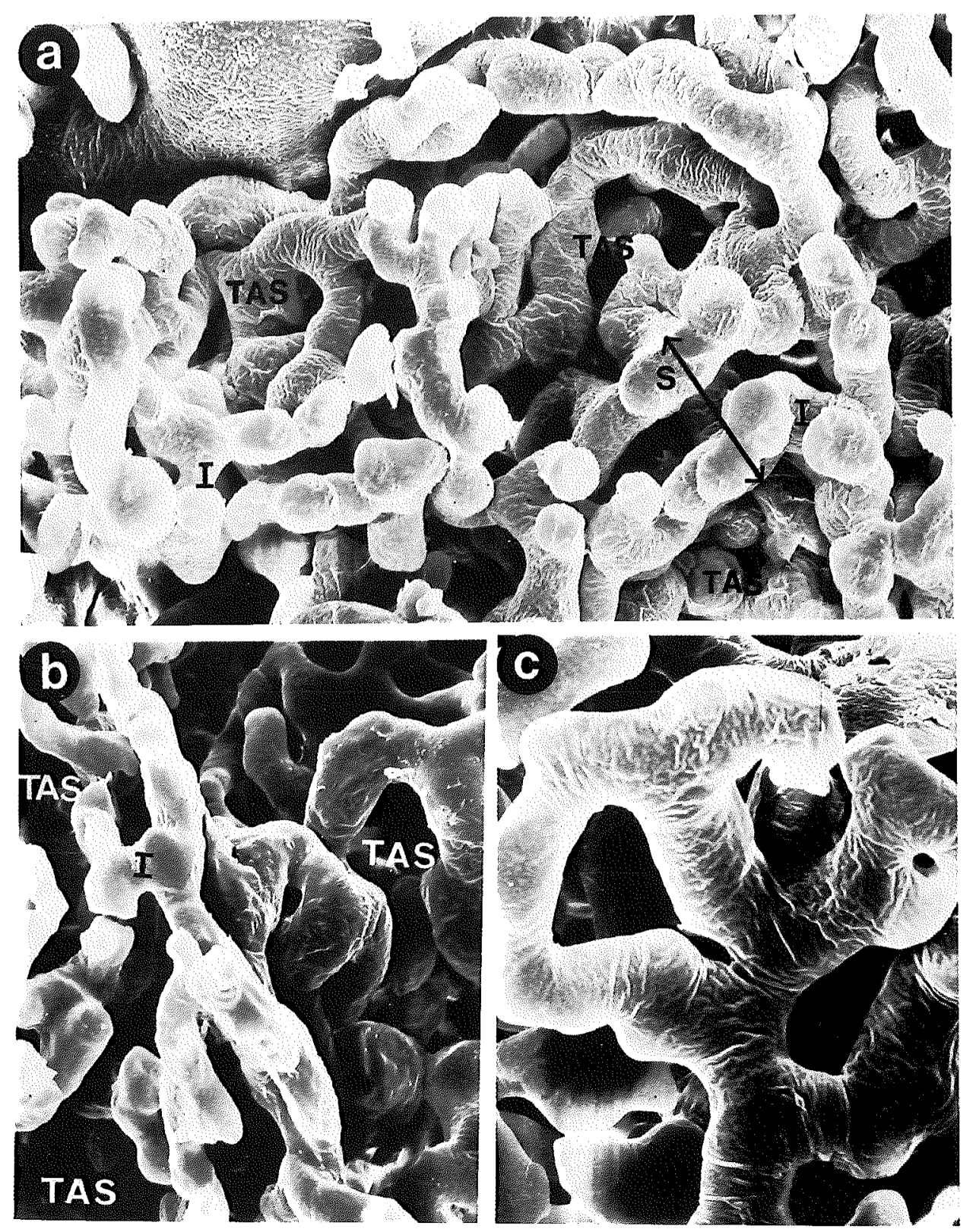

Fig. 6 Scanning electron microscopy of neonatal lung plastic cast. Fig. a shows a double capillary plexus in the septum (S) surrounding each terminal air sac (TAS). $\times 915$. These plexi have interconnections (I) through the interstitial space (b). $\times 1,100$. In $c$, the anastomotic plexus lining the TAS is shown. $\times 1,460$ 
These areas, or holes, were crossed by isolated vessels of erratic orientation from which short, blind-ending branches protruded (Fig. 4).

\section{Neonatal Lung}

Tissue specimens Macroscopically, the neonatal lung specimens showed an almost uniform, black fracture surface, indicating an even vascular perfusion with osmium (Fig. 2b). Under the SEM, the tissue appeared expanded, with spherical terminal air sacs. The blood vessels were generally devoid of blood cells, although in some areas, especially around larger blood vessels and airways, resistance to perfusion appeared to be greater, i.e. washout of blood elements was less complete (Fig. 5).

Vascular casts The vascular bed of neonatal lung was uniformly cast. Each terminal air sac was lined with a capillary plexus of the same structural design as in the foetus. A greater proportion of each peri-terminal air sac plexus was completely filled (Fig. 6).

\section{DISCUSSION}

The methods used in this study allowed a comparison of the pulmonary microvasculature of foetal rabbits with that of neonatal rabbits over the first 30 min of postnatal life.

In the foetal lung, there appeared to be areas of markedly high resistance to perfusion, preventing blood washout and plastic casting. These regions contained a number of adjacent potential air sacs. The high vascular resistance is thus most likely due to a narrowed common supply vessel, probably a muscular arteriole feeding a lung lobule. The sharp nature of the boundaries between differing 'resistance' areas was consistently observed and supports such a proposal. Hence it appears that the foetal lung is functioning as a number of subunits which accommodate different proportions of the blood flow. Haemodynamically, this suggests that high foetal pulmonary vascular resistance is maintained because some $50 \%$ of these vascular units carry little or no flow at a particular moment, while the rest have a much larger blood flow, rather than because the lung vascular resistance is uniformly raised and distributed throughout the foetal lung.

Distribution of the pulmonary blood flow in such a manner may perhaps explain the metabolic cycles of activity observed by Towers (9) with regard to secretory rhythms of glycogen metabolism and secretory/excretory rhythms of the phospholipid component of surfactant. Towers correlated this metabolic activity with histologically evident areas of increased parenchymal expansion. Such expanded areas were also seen in our study; this associated feature of these perfused areas may reflect the localization of the site of foetal lung liquid production, with active secretion of the liquid distending only those terminal air sacs which have a currently perfused vascular bed. Additionally the blood itself may engorge the tissue of the inter-terminal air sac septum, distending the perfused terminal air sacs in an 'erectile-like' manner.

Given such a model of differentially perfused vascular units in the foetal lung, and yet the uniformity of development of the neonatal lung, it is unlikely that large regions of the foetal lung are continually hypoperfused while the remainder always carry the majority of the blood flow. It seems probable that individual units alternate so that a constant number has a high resistance, at any time, but not always the same ones.

In the nonperfused areas of the foetal lung, occasional vessels were observed which were devoid of blood (or were filled with plastic). Their precise location in relation to other elements within the lung parenchyma could not be definitely ascertained, but they may correspond to the 'corner' vessels of alveoli in adult lungs referred to by Glazier et al. (4), and may provide some nutritional source for the surrounding tissue whilst the resistance of most of the surrounding microvessels is high.

After 30 min of breathing, all terminal air sacs were expanded and the pulmonary capillaries were uniformly perfused. Such a marked contrast suggests that the features seen in the foetus are real. The postnatal fall in pulmonary vascular resistance to $2.5-5.0 \%$ of the foetal value is considered to be due to dilatation and recruitment of arterioles $(5,7)$. Capillary recruitment (10) and distension (11) are considered important in changing adult pulmonary resistance.

In the foetus there appeared to be some 
contribution to pulmonary vascular resistance at the capillary level. This was evidenced in the foetal lung casts by the incomplete filling of the capillary plexus in even the 'well-cast' areas and in the tissue specimens by a few capillaries, in well washed-out areas, that still contained blood elements. The increased resistance at this level could be due to 1) physical forces, to the folding and compression of vessels in the compact foetal lung, or 2) contractile elements in the interstitium (e.g. myofibroblasts or pericytes) or in endothelial cells.

From our observations neonatal pulmonary adaptation appears to involve 1) recruitment and dilatation of arterioles and 2) capillary recruitment; capillary distension was not assessed. Hence the entire pulmonary vascular bed is 'opened up' at birth, accommodating the increased blood flow at a reduced perfusion pressure.

Supported by research grants from the National Health and Medical Research Council of Australia, the Flinders University Research Committee and research scholarships to Dr Lipsett from the National Heart Foundation of Australia and the AMSA-Lily Research Foundation.

Received for publication 21 September 1987

\section{REFERENCES}

1. Gannon B. J. (1981) Preparation of microvascular corrosion casting media: procedure for partial polymerization of methyl methacrylate using ultraviolet light. Biomedical Res. 2, Suppl., 227-233

2. Gil J., Bachofen H., Gehr P. and Weibel E. R. (1979) Alveolar volume-surface area relation in air- and saline-filled lungs fixed by vascular perfusion. J. Appl. Physiol. 47, 990-1001

3. Glauert A. M. (1975) Fixation, dehydration and embedding of biological specimens. In Practical Methods in Electron Microscopy (ed. Glauert A. M.) Vol. 3, Pt. 1, North Holland, Amsterdam

4. Glazier J. B., Hughes J. M. B., Maloney J. E. and West J. B. (1969) Measurements of capillary dimensions and blood volume in rapidly frozen lungs. J. Appl. Physiol. 26, 65-76

5. Haworth S. G. and Hislop A. A. (1981) Adaptation of the pulmonary circulation to extrauterine life in the pig and its relevance to the human infant. Cardiovasc. Res. 15, 108-119

6. Murakami T. (1971) Application of the scanning electron microscope to the study of the fine distribution of the blood vessels. Arch. Histol. Japon. 32, 445-454

7. Rudolph A. M. (1979) Fetal and neonatal pulmonary circulation. Annu. Rev. Physiol. 41, 383-395

8. Rudolph A. M. and Heymann M. A. (1974) Fetal and neonatal circulation and respiration. Annu. Rev. Physiol. 36, 187-207

9. Towers B. (1968) The foetal and neonatal lung. In Biology of Gestation (ed. Assali N.) New York Academic Press, New York, pp. 189-221

10. Warrell D. A., Evans J. W., Clarke R. O., Kingaby G. P. and West J. B. (1972) Pattern of filling in the pulmonary capillary bed. J. Appl. Physiol. 32, 346-356

11. West J. B., Schneider A. M. and Mitchell M. M. (1975) Recruitment in networks of pulmonary capillaries. J. Appl. Physiol. 39, 976-984 